\title{
Prenatal exposure to tobacco and future nicotine dependence: population-based cohort study
}

\author{
Mina Rydell, Sven Cnattingius, Fredrik Granath, Cecilia Magnusson and Maria Rosaria Galanti
}

\section{Background}

Maternal smoking during pregnancy may increase the risk of nicotine dependence, especially in girls, but data are conflicting and confounding by other familial factors cannot be ruled out.

\begin{abstract}
Aims
To clarify the relationship between prenatal tobacco exposure and adolescent tobacco uptake and dependence in boys and girls respectively, while taking confounding factors into close consideration.
\end{abstract}

\section{Method}

We conducted a prospective longitudinal study, comprising 3020 swedish youths followed from 11 to 18 years of age. Exposure and outcome information was elicited via selfadministered parental and repeated youth questionnaires. Hazard ratios (HRs), odds ratios (ORs) and corresponding 95\% confidence intervals (CIS) were calculated as measures of associations

\section{Results}

Girls prenatally exposed to maternal tobacco use had a twoto threefold increased odds of experiencing a high number of withdrawal symptoms $(\mathrm{OR}=2.83,95 \% \mathrm{Cl} 1.68-4.87)$, craving for tobacco $(\mathrm{OR}=2.04,95 \% \mathrm{Cl} 1.28-3.32)$ and heavy tobacco use (five or more cigarettes or snus dips per day) $(\mathrm{OR}=1.93$, 95\% Cl 1.30-2.86). These associations were weaker among boys, and did not reach formal statistical significance. Associations between prenatal tobacco exposure and onset of regular tobacco use in both genders appeared to be mostly explained by parents' social position and postnatal smoking behaviour.

\section{Conclusions}

Prenatal exposure to tobacco is linked to an increased risk of nicotine dependence among adolescent girls.

\section{Declaration of interest}

M.R.G. is responsible for the tobacco prevention activities carried out by the Department of Public Health Sciences on behalf of Stockholm County Council. F.G. participates in a study funded by Pfizer, aimed at studying the potential adverse birth outcomes of varenicline. This project is a part of fulfilling the US Food and Drug Administration/European Medicines Agency's requirement of post-marketing surveillance and has no link to the presented work.
Knowledge about determinants of tobacco use and of nicotine dependence is required for effective tobacco control. Prenatal exposure to tobacco has been implicated as such a determinant, since nicotine crosses the placenta barrier, and can result in even higher fetal than maternal blood concentrations. ${ }^{1}$ Nicotine acetylcholine receptors are present in the fetal brain from the fourth week of gestation onwards, ${ }^{1}$ and it has been suggested that exposure to nicotine can lead to sensitisation and early disruption of acetylcholine-mediated pathways (teratogenesis). ${ }^{2}$ Ultimately, these functional and perhaps morphological changes could result in an enhanced vulnerability to tobacco dependence. ${ }^{1}$ This hypothesis is supported by findings from animal studies, ${ }^{2,3}$ and from studies on human cell systems. ${ }^{4}$

However, neurological teratogenesis is not the only mechanism by which prenatal tobacco exposure may be linked to tobacco use and/or nicotine dependence later in life. The causal model ${ }^{5}$ presented in Fig. 1 posits that maternal tobacco use can be associated with use and dependence through: (a) a common genetic liability; ${ }^{6}$ (b) direct behavioural influence of parental postnatal tobacco use; ${ }^{7}$ and (c) influence from common social factors ${ }^{7}$ on both maternal and children's behaviour. In light of the complexity of this causal model, it is not surprising that the few existing studies of tobacco uptake have yielded inconsistent results, including reports of positive, ${ }^{8-18}$ null ${ }^{19,20}$ or even inverse associations. $^{21,22}$ Stronger evidence of a positive and causal association have, however, been found in relation to nicotine dependence. $^{8-10,22,23}$ Our understanding of the potential brain priming impact of fetal nicotine exposure is thus hampered by incomplete control of confounding in prior studies. In addition, there are no data on smokeless tobacco use, either as a source of prenatal exposure to nicotine or as an offspring outcome.
The primary purpose of this study, based on a large prospective cohort of youths, was to clarify whether there is an association between prenatal tobacco exposure and risk of tobacco use and dependence during adolescence, after controlling for the influence of parental postnatal tobacco use as well as familial social position. Secondarily, we wanted to assess whether such an association differs between genders. In fact, animal studies indicated a stronger effect of prenatal exposure to nicotine among females, ${ }^{3}$ while previous epidemiological studies were inconsistent. $^{12,19}$

\section{Method}

\section{Study population}

The BROMS (Children's Smoking and Environment in Stockholm County) cohort study was conducted in Stockholm County between 1998 and 2005, with the main purpose of studying development and determinants of tobacco use in adolescence. The study was approved by the ethical board at Huddinge University Hospital and has been described in detail elsewhere. ${ }^{24,25}$ Briefly, 3020 children recruited during the fifth grade of compulsory school (average age 11 years) were followed until 3 years after compulsory school (average 18 years), resulting in one baseline assessment and six follow-up surveys. At each survey, the children reported their past and current tobacco use by means of a structured questionnaire. The annual participation rate ranged from 87 to $96 \%$, with $69 \%$ of the adolescents participating in all surveys. At baseline, the children's parents were also asked to complete a questionnaire eliciting information on parental characteristics (participation rate $99 \%$ ). ${ }^{24}$ 


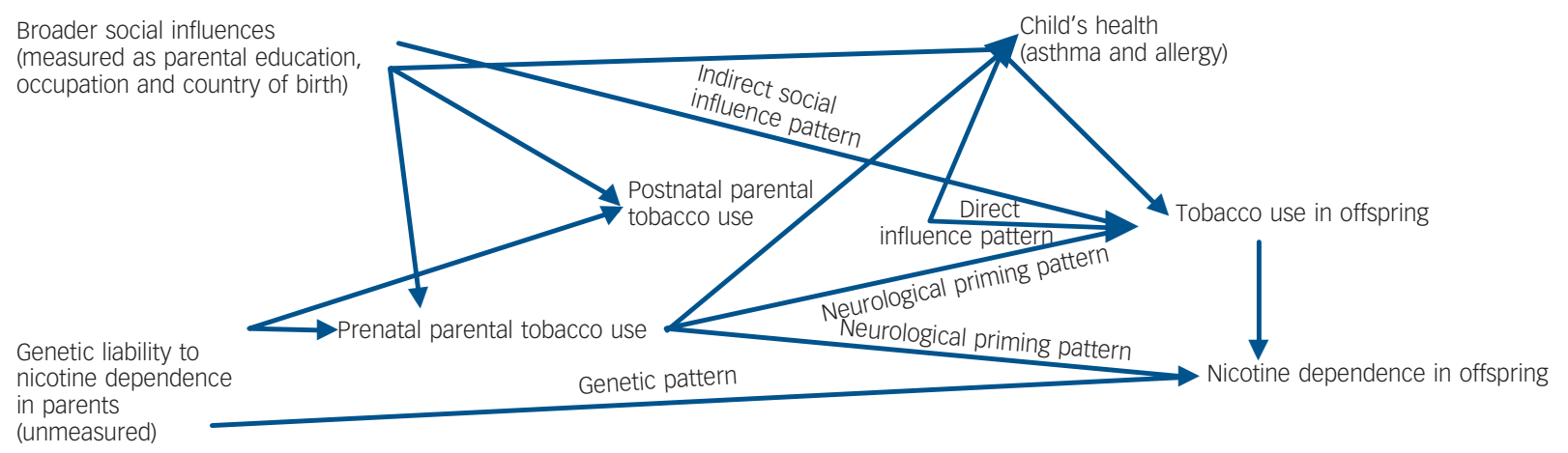

Fig. 1 Possible associations between prenatal exposure to tobacco, tobacco use, and nicotine dependence in offspring.

\section{Measures}

\section{Exposure}

Information regarding prenatal exposure to tobacco was reported from parents at baseline. The mother and father were separately asked whether they smoked or used snus (the Swedish form of moist oral snuff) when the mother was pregnant with the index child. Parental tobacco use was investigated according to both timing (use during the first or second/third trimesters of pregnancy) and frequency (daily or occasional).

Prenatal tobacco exposure from the maternal source was defined as the mother's self-reported use of any tobacco (cigarettes and/or snus), categorised as: any $v$. none. As very few mothers changed their tobacco use during the pregnancy, duration of use was not considered.

Furthermore, we considered the cumulative passive exposure to the fetus, deriving from maternal tobacco use and from paternal smoking, resulting in one variable with four mutually exclusive categories:

(a) exposure from both parents (father smoked at least occasionally during the index pregnancy and mother smoked and/or used snus at least occasionally);

(b) exposure to maternal tobacco use only (mother smoked and/ or used snus at least occasionally, while father did not use tobacco at all, or only used snus);

(c) exposure to paternal smoking only (father smoked at least occasionally, while mother did not use tobacco at all);

(d) no prenatal exposure to tobacco use from parental source (no maternal use of tobacco, no paternal smoking).

If non-use of tobacco was reported by a parent during the first trimester of pregnancy, missing information during the second and third trimester was categorised as non-use, since initiation of tobacco use during pregnancy is very rare. ${ }^{26}$ Incomplete information regarding either mother's or father's use of tobacco during pregnancy was coded as missing for the combined measure of parental tobacco use. Due to missing values, 142 study participants were excluded from analyses where maternal tobacco use during pregnancy was used as the exposure variable and 327 participants were excluded from analysis where any prenatal tobacco exposure from a parental source (i.e. using information on both maternal and paternal tobacco use) was used.

\section{Outcome}

Outcome measures included: onset of any current use and of daily use of tobacco during follow-up; lifetime experience of intense craving for tobacco; lifetime experience of withdrawal symptoms in case of discontinuation of tobacco use; and total current tobacco consumption. The latter three outcomes were based on reports elicited at the age of 17 years.

Onset of tobacco use. Combining answers from survey questions, an average index of total annual consumption was calculated separately for cigarettes and snus. Two outcome variables were analysed for each type of tobacco: onset of any current use (having smoked at least 12 cigarettes or used at least 12 snus dips during the year preceding the survey); and onset of daily use (at least 240 cigarettes or snus dips during the year preceding the survey). Children who were current users at baseline $(n=10)$, and those who did not take part in any follow-up survey $(n=9)$ were excluded from the analyses of onset of tobacco use.

Measures of nicotine dependence and withdrawal symptoms. The study population for the analysis of these outcomes consisted of adolescents who reported any current use of tobacco and who participated in the survey conducted at the age of 17 years ( 2 years after compulsory school) when the assessment of nicotine dependence and withdrawal symptoms was conducted for the first time. Details regarding this assessment have been reported previously. $^{25}$

Among the items used to identify nicotine dependence included in the survey, ${ }^{25}$ we restricted the current analyses to lifetime reports of intense urge to use tobacco (craving). In fact, craving has been found to occur early and frequently in adolescents' smoking trajectories, and to be independent of withdrawal symptoms. ${ }^{27,28}$ In addition, it has been argued that the presence of this symptom is sufficient to make a diagnosis of nicotine dependence, based on a neurobehavioural model predicting drug administration and escalation. ${ }^{29}$

The following withdrawal symptoms after discontinued tobacco use were investigated: craving, feeling upset or tense, impaired concentration, feeling depressed, increased appetite/ weight, heart palpitation, nausea, anxiety and sleeping problems (all categorised as yes $v$. no). An index of these items was created, and dichotomised as experienced four or more symptoms $v$. fewer, based on the median value. The number of symptoms in this analysis represents a conservative estimate because of partially missing answers.

Tobacco consumption. A variable for total tobacco consumption at age 17 was derived, in order to distinguish between high (at least five cigarettes and/or snus dips per day), low (less than five cigarettes and/or snus dips per day) and no consumption.

\section{Other covariates}

Postnatal exposure to parental tobacco use was assessed through the children's surveys between the ages of 11 and 14 years (baseline 
through follow-up wave three). Answers obtained separately for each parent were combined into a summary variable where a child was considered exposed to postnatal tobacco use if the child at any time point recalled either parent using any type of tobacco. Missing information on no more than two occasions, in combination with reports of non-use on the other occasions, was regarded as parental non-use. Apart from this instance, a combination of negative and missing information for any variable was generally categorised as missing.

Family's socioeconomic position was assessed through selfreported information on parental occupation and education. Occupation was coded according to the Swedish socioeconomic classification from Statistics Sweden. Parental education, defined as the number of years each parent had attended school, was categorised as compulsory ( $\leqslant 9$ years), intermediate ( $10-12$ years) or high ( $>12$ years). For the purpose of this study, the mother's occupation and education were primarily used. We also analysed a combined measure of higher education for both parents, coded as: both parents, either parent or neither with college education.

Information on parents' country of birth was reported by the children at baseline and categorised as both parents, either parent or neither parent born in a Nordic country (i.e. Sweden, Denmark, Finland, Iceland and Norway). Childhood health events that may have influenced tobacco habits were obtained through reports from school nurses. For this analysis, we used information on diagnoses of asthma and allergies (coded as yes $v$. no).

\section{Statistical analyses}

Study populations and analytical samples for the outcomes included in this analysis are reported in Table 1. SAS version 9.2 for Windows was used for all analyses. Onset of tobacco use was analysed by means of Cox regression, with failure time corresponding to the year during which monthly or daily use was first reported. Follow-up time in absence of failure was

\begin{tabular}{|c|c|c|}
\hline Outcome & Inclusion criteria & $\begin{array}{l}\text { Analytical } \\
\text { sample, } n\end{array}$ \\
\hline $\begin{array}{l}\text { Current } \\
\text { smoking }\end{array}$ & $\begin{array}{l}\text { Cohort participants with at least one } \\
\text { follow-up assessment, no previous current } \\
\text { smoking at baseline }\end{array}$ & 3003 \\
\hline $\begin{array}{l}\text { Daily } \\
\text { smoking }\end{array}$ & $\begin{array}{l}\text { Cohort participants with at least one follow-up } \\
\text { assessment, no previous daily smoking at } \\
\text { baseline }\end{array}$ & 3008 \\
\hline $\begin{array}{l}\text { Current } \\
\text { snus use }\end{array}$ & $\begin{array}{l}\text { Male cohort participants with at least one } \\
\text { follow-up assessment, no previous current } \\
\text { snus use at baseline }\end{array}$ & 1529 \\
\hline $\begin{array}{l}\text { Daily snus } \\
\text { use }\end{array}$ & $\begin{array}{l}\text { Male cohort participants with at least one } \\
\text { follow-up assessment, no previous daily snus } \\
\text { use at baseline }\end{array}$ & 1531 \\
\hline Craving & $\begin{array}{l}\text { Cohort participants with at least one follow-up } \\
\text { assessment, who at any time reported current } \\
\text { tobacco use between the age of } 11 \text { and } 17 \\
\text { years, and answered the question about } \\
\text { feeling a strong urge to use tobacco at age } 17\end{array}$ & 897 \\
\hline $\begin{array}{l}\text { Withdrawal } \\
\text { symptoms }\end{array}$ & $\begin{array}{l}\text { Cohort participants with at least one follow-up } \\
\text { assessment, who at any time reported current } \\
\text { tobacco use between the age of } 11 \text { and } 17 \\
\text { years and answered the questions on } \\
\text { withdrawal symptoms at age } 17\end{array}$ & 747 \\
\hline $\begin{array}{l}\text { Tobacco } \\
\text { consumption }\end{array}$ & $\begin{array}{l}\text { Cohort participants who answered the } \\
\text { questionnaire at age } 17, \text { with information } \\
\text { on total annual amount of both cigarettes } \\
\text { and snus used }\end{array}$ & 2587 \\
\hline
\end{tabular}

censored at refusal to continue participation, death or end of follow-up, whichever occurred first. For individuals with intermittent missing information, we assumed that tobacco-using status remained the same until a positive report was obtained. Hazard ratios (HRs) and corresponding 95\% confidence intervals (CIs) were used as measures of association and its precision. The assumption of proportionality was verified via calculation of Odds ratios (ORs) of tobacco onset for each year of follow-up, producing similar point estimates with overlapping CIs. Odds ratios of craving, withdrawal symptoms and tobacco consumption at the age of 17 years were calculated through logistic regression.

Adjustments were made for potential confounders following the causal model illustrated in Fig.1. In brief, social characteristics assumed to have a direct or indirect effect on the child's tobacco use and nicotine dependence, as well as the child's health, were considered potential confounders. In multivariate models, we only adjusted for those characteristics that were associated with the respective outcomes in univariate models and modified the crude association between exposure and outcome by at least $10 \%$.

All analyses were done separately among boys and girls. Analyses of snus uptake were restricted to boys, since such uptake was rare in girls.

\section{Results}

Sociodemographic characteristics of the study population are shown in Table 2. The majority of the study participants were 11 years or younger at baseline, and had highly educated parents

Table 2 Prevalence of prenatal tobacco exposure in relation to baseline characteristics

\begin{tabular}{|c|c|c|}
\hline & $n$ & $\begin{array}{c}\text { Prenatally exposed } \\
\text { to maternal use } \\
\text { of tobacco, \% }\end{array}$ \\
\hline \multicolumn{3}{|l|}{ Gender } \\
\hline Male & 1467 & 27.3 \\
\hline Female & 1411 & 27.4 \\
\hline \multicolumn{3}{|l|}{ Age } \\
\hline 11 years or younger & 2480 & 26.9 \\
\hline 12 years or older & 398 & 30.2 \\
\hline \multicolumn{3}{|l|}{ Maternal education ${ }^{a}$} \\
\hline Compulsory & 328 & 43.6 \\
\hline Intermediate & 1089 & 33.1 \\
\hline High & 1403 & 19.5 \\
\hline \multicolumn{3}{|c|}{ Parents with college education ${ }^{a}$} \\
\hline None & 971 & 36.8 \\
\hline One & 734 & 26.7 \\
\hline Both & 928 & 15.1 \\
\hline \multicolumn{3}{|l|}{ Maternal occupation ${ }^{a}$} \\
\hline Unskilled worker & 378 & 37.8 \\
\hline Skilled worker & 256 & 30.9 \\
\hline Low-level clerk & 457 & 28.5 \\
\hline Middle-level clerk & 763 & 24.3 \\
\hline High-level clerk & 465 & 19.1 \\
\hline Self-employed & 129 & 23.3 \\
\hline Not in the labour force & 313 & 31.3 \\
\hline \multicolumn{3}{|c|}{ Parents' born in the Nordic countries ${ }^{a}$} \\
\hline Both parents & 2304 & 28.4 \\
\hline One parent & 253 & 27.7 \\
\hline Neither parent & 236 & 16.5 \\
\hline \multicolumn{3}{|c|}{ Parents' postnatal tobacco use $\mathrm{e}^{\mathrm{a}, \mathrm{b}}$} \\
\hline Never & 1277 & 9.8 \\
\hline Ever & 1446 & 44.3 \\
\hline \multicolumn{3}{|c|}{$\begin{array}{l}\text { a. P-value for } \chi^{2} \text {-test }<0.001 \text {. } \\
\text { b. Parents' postnatal tobacco use includes any parental smoking or snus use during } \\
\text { the index child's age of } 11-14 \text { years. }\end{array}$} \\
\hline
\end{tabular}


born in Sweden or other Nordic countries. About 27\% of the participants with available information were prenatally exposed to maternal tobacco use, while $43 \%$ were prenatally exposed to any parental tobacco use. Expectedly, the proportion of individuals exposed to prenatal maternal use of tobacco increased with decreasing level of parental education, and was higher among pregnancies to blue collar workers compared with white collar workers, but was markedly lower if neither parent was born in a Nordic country. Furthermore, $84 \%$ of the children prenatally exposed to maternal tobacco use were also exposed to parents' postnatal tobacco use, in contrast with $41 \%$ of those unexposed. During follow-up, 1007 children became current smokers (41.7\% of those exposed to prenatal maternal tobacco use, compared with $30.6 \%$ of those unexposed), of which 761 started smoking daily $(33.7 \%$ of those exposed to prenatal maternal tobacco and $22.2 \%$ of those unexposed). The corresponding figures for any current snus use were $38.3 \%$ of those exposed and $29.2 \%$ of those unexposed, while $34.1 \%$ and $24.8 \%$ for those exposed and unexposed respectively took up daily snus use.

Table 3 gives the crude and adjusted HRs for onset of daily smoking. In both genders, there was a significant crude association with prenatal exposure to tobacco and any smoking in adolescence. The associations were, however, considerably attenuated after adjustment for parental postnatal use of tobacco and parental education. Exposure to both parents' prenatal use of tobacco was associated with higher risks of daily smoking than exposure to one parental source only. Among boys, daily smoking remained associated with prenatal exposure from both parents and from the father only, after adjustment for potential confounders, while among girls the associations were no longer evident after this adjustment (Table 3). Very similar results were obtained when any current smoking was analysed as an outcome, as well as in the analysis of any current and daily snus use among boys (data not shown).

Odds ratios of lifetime experience of nicotine dependence and withdrawal symptoms at age 17 are shown in Table 4. Compared with those unexposed, girls prenatally exposed to maternal tobacco use had twofold higher adjusted odds of feeling a strong urge to use tobacco (craving), while no association was evident among boys.

Having experienced four or more withdrawal symptoms after discontinuation of tobacco use was more common among children prenatally exposed to parental tobacco compared with those unexposed (Table 4). Separate analyses by gender again showed statistically significant associations only among girls, with ORs of 3.28 if both parents used tobacco, and of 2.30 if only the mother did, but no association with paternal smoking only.

Table 5 shows the adjusted ORs of being a low (less than five cigarettes and/or snus dips per day) or heavy consumer (five or more cigarettes and/or snus dips per day) of tobacco at the age 17 of years. After adjusting for parental postnatal use of tobacco and parental education, girls prenatally exposed to maternal tobacco use had twofold increased odds of being heavy consumers of tobacco compared with girls unexposed to maternal tobacco use, whereas no such an association could be found in boys. Prenatal tobacco exposure was not associated with low consumption of tobacco.

\section{Discussion}

In this large prospective study we found clear associations between maternal tobacco use during pregnancy and nicotine dependence as well as heavy smoking among adolescent girls - but not boys. These findings were robust, also when important confounding factors including parental social position and postnatal tobacco use were accounted for. However, prenatal exposure to tobacco was not linked to onset of regular tobacco use in adolescence in a straightforward way. In fact, the association appeared to be confined to boys, and was as strong for maternal as for paternal sources, probably indicating residual confounding. These results are compatible with the theoretical model in Fig.1, postulating social influences as the main causal pathway to substance use initiation, while the importance of intra-uterine exposure would be revealed in the clinical manifestation of dependence (such as strong urge to use tobacco and heavy consumption).

All previous studies where nicotine dependence was analysed in relation to prenatal exposure to maternal smoking showed associations of direction and magnitude very similar to ours. ${ }^{8-10,22,23}$ We add to this knowledge that the strength of withdrawal symptoms appears associated with prenatal exposure to tobacco in a dose-response fashion.

The lack of a clear association between prenatal exposure to tobacco and daily smoking in our study was rather surprising, as onset of daily smoking is an obvious indication of progression in smoking behaviour, which may be related to early onset of dependence. ${ }^{30}$ In fact, the majority of earlier studies did report such an association, ${ }^{8-18}$ although others did not ${ }^{19,20}$ or presented

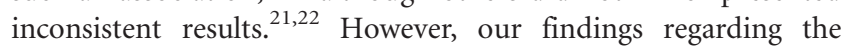
risk of high tobacco consumption in late adolescence suggest that transition to more established and regular tobacco use (as opposed to initial episodes of tobacco use) is associated with prenatal exposure to tobacco, which is in line with previous results. $^{8,15,22}$

Comparison of findings between our and other studies is hampered by differences in study designs and population characteristics. For instance, many studies reporting an association between prenatal tobacco exposure and tobacco use in offspring were based on relatively small and/or high-risk samples of pregnant mothers, with low retention at follow-up. ${ }^{8-15,17,18,20,21}$ Also, some studies employed retrospective assessment of prenatal exposure, ${ }^{8-11,15,16}$ in some instances even based on reports from the offspring, ${ }^{8,10}$ thus potentially being prone to recall bias. In addition, differences in ages and outcome definition may have contributed to discrepancies. In our analysis, spanning from early to late adolescence, daily tobacco use was categorised as average use of 20 cigarettes or snus dips or more per month during the previous year. Therefore, it is possible that many of these young daily users were far from having completed the progression to the established and intensive consumption pattern considered in other studies. ${ }^{8,10,11,16,18}$ The association we found with intense daily use at age 17 speaks in favour of this interpretation. However, confounding by direct and indirect postnatal social influences is the most important concern when interpreting the current evidence. For instance, most previous studies did not adjust for exposure to paternal postnatal influences, as we did in our analysis.

\section{Gender differences}

The question of a gender-specific pattern of tobacco progression and nicotine dependence associated with fetal exposures among humans is still unsettled. In fact, four of ten epidemiological studies presenting gender-specific analyses found no difference, ${ }^{9,12,17,20}$ stronger associations with lifetime-smoking were found in three studies for females, ${ }^{14,15,19}$ and in one study for males. ${ }^{21}$ The two remaining studies showed opposite gender patterns depending on the outcome under study. ${ }^{8,22}$

We found that the associations between prenatal exposures and excess risks of nicotine dependence (Table 4) and high consumption of tobacco (Table 5) were stronger among girls than 

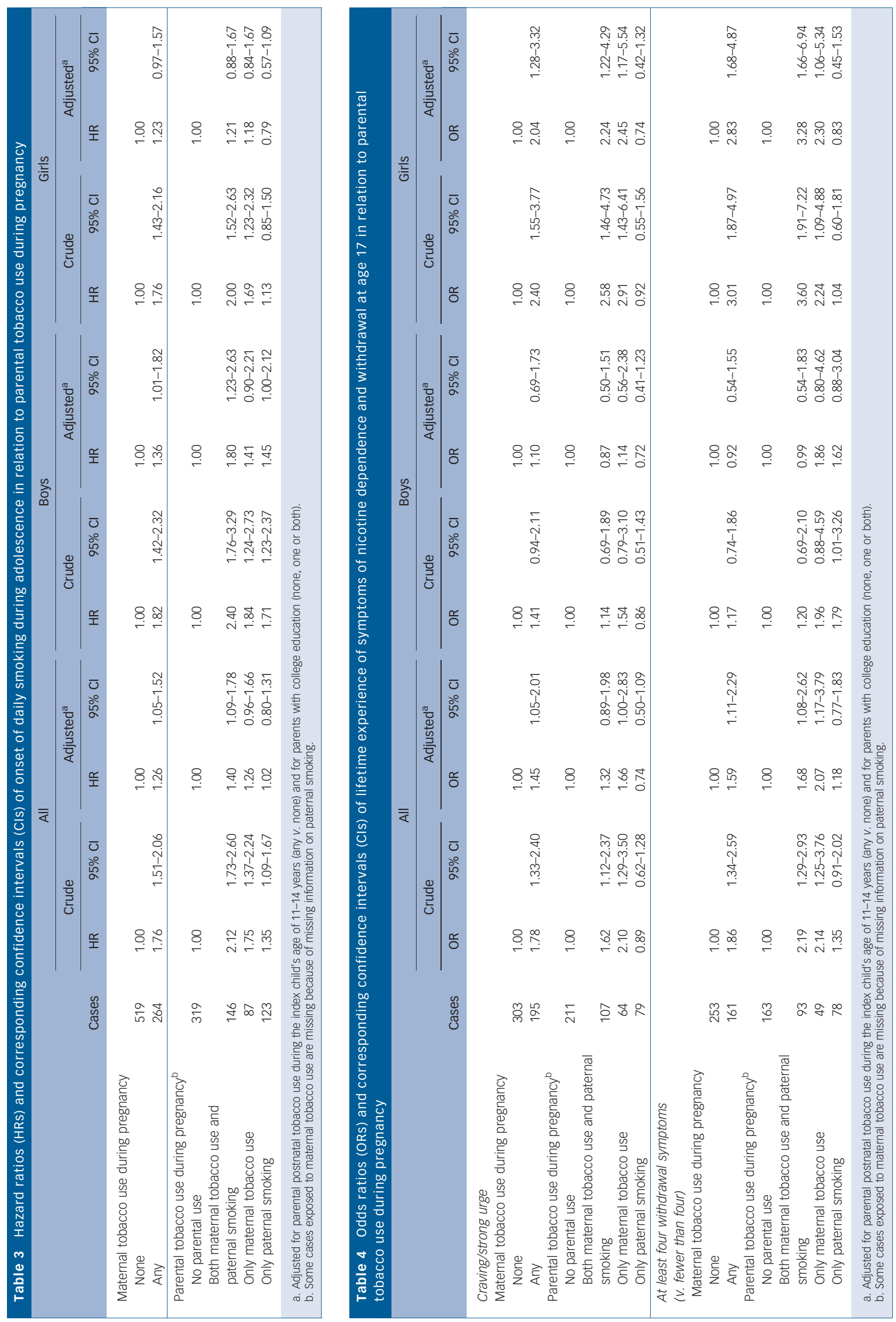


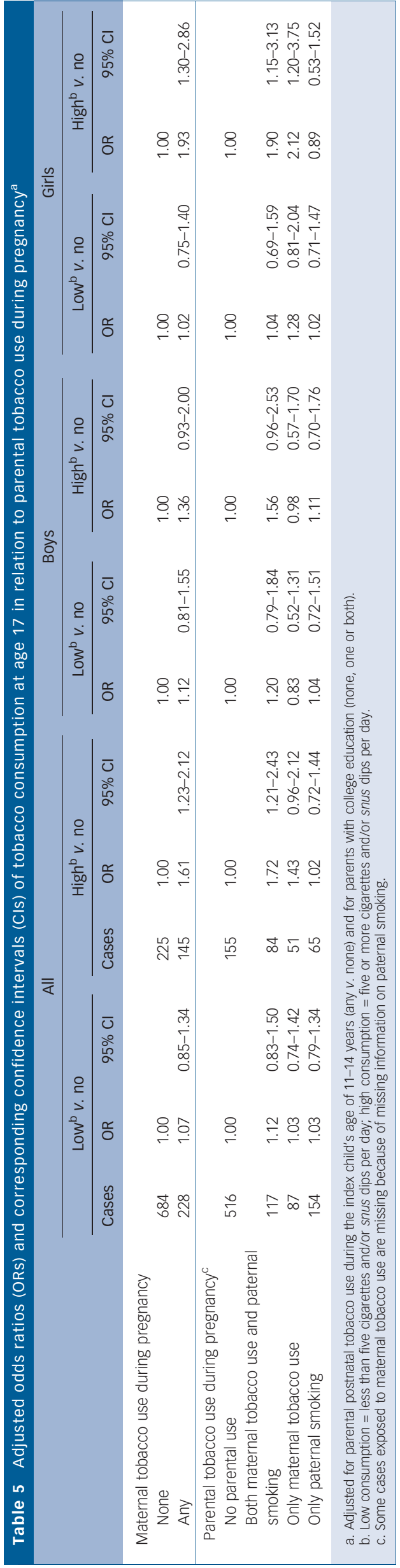

boys. This finding adds strength to the hypothesis of a stronger vulnerability of the female fetal brain to nicotine neurotoxicity, ${ }^{3}$ a vulnerability that may be related to modification of the brain response to nicotine modulated by oestrogens. ${ }^{31}$ In fact, such a gender-specificity was not seen with the uptake of current or daily tobacco use (Table 3).

Nicotine dependence is difficult to assess at young ages, when its features may be partly different from those seen among adults. ${ }^{32}$ Therefore, discrepancies between studies may be related to methods and timing of this assessment. To investigate nicotine dependence we used a single item suitable to adolescents' low intensity and low level of regularity in using tobacco, ${ }^{32}$ while other studies relied on complete scales mostly used among adults. $^{8-10,22,23}$ Further, our study included the outcomes of both smoking and smokeless tobacco use, two behaviours with a recognised uneven gender distribution in the Swedish population. ${ }^{33}$ For instance, only $6.6 \%$ of girls became current snus users at any time during follow-up in our sample. It is possible that the lower frequency of quit attempts found among exclusive snus users compared with pure smokers in this cohort ${ }^{25}$ accounts for the lack of detectable associations or paradoxical findings concerning symptoms of dependence and withdrawal among boys. Other explanations for the somewhat inconsistent patterns of boys' tobacco use in relation to exposure may be the considerable group of dual users, or residual confounding from parental postnatal influences. Finally, the separate analyses by gender presented in this study were based on small samples, although the sample size was similar in boys and girls.

\section{Strengths and limitations}

This study has several strengths. First, it was based on a large longitudinal sample with high retention at follow-up. Prenatal exposures were assessed prospectively and outcomes were assessed through repeated measurements over 7 years. Recognising that maternal smoking may not be the only source of tobacco toxicants to the fetus, we also included information on maternal snus use and paternal smoking during the index pregnancy (as a possible source of passive prenatal tobacco exposure). Although the distant recall of pregnancy tobacco use by the parents might have introduced some misclassification, a validation study among mothers of the children in the BROMS cohort showed good concordance with self-reports of smoking elicited during pregnancy. ${ }^{34}$ This good concordance is further supported by findings from an American study that showed high congruency between retrospective reports of pregnancy smoking, prospective reports and levels of urinary cotinine. ${ }^{35}$ Likewise, a validation study of a subsample of this cohort's participants showed a $98 \%$ concordance between self-reported no use of any tobacco in the past month and cotinine concentration in saliva, with a sensitivity of $90 \%$ and specificity of $93 \% .{ }^{34}$ Finally, we could adjust for major confounders chosen a priori, ${ }^{5}$ according to a theoretical model. Parental use of tobacco during childhood and adolescence is one of the factors with the strongest impact on adolescent smoking, ${ }^{36}$ probably acting through both role modelling and availability of tobacco. In this study, we took advantage of repeated reports on parent's tobacco use as experienced by their children (i.e. the final target of social influences).

Some limitations should be kept in mind when interpreting our results. Children of highly educated parents born in Nordic countries were overrepresented, because of initial selection owing to parental consent. ${ }^{24}$ This may have affected the power of the study to detect weak associations, because of low rates of daily smoking among children. However, if parents' social status were a moderator of the effect of prenatal exposure to tobacco, the bias 
introduced by this selection would most likely result in underestimation of the association under study. We could not adjust for other potential confounders such as parenting style, parental comorbidity, exposure to passive smoking as an infant, ${ }^{36}$ other early life influences and genetic liability to nicotine dependence, well documented in previous studies on twins. ${ }^{6}$ However, the gender differences found in our study would suggest genetic confounding to have a minor role.

Findings from this study indicate that symptoms of nicotine dependence and progression in tobacco use in adolescent girls can be linked with nicotine exposure in utero. This suggests that tobacco dependence should be added to the risks of passive exposure during the prenatal life. Female smoking prevalence above $20 \%$ is common in several countries. ${ }^{37}$ It should also be noted that even in Sweden, with a low overall prevalence of smoking among women and in pregnancy in particular, there is a gap still to be tackled concerning young mothers and women with limited education, ${ }^{38}$ a clear priority in public health programmes.

\section{Funding}

This study was funded with grant 2008-0876 from the Swedish Council for Working Life and Social Research. The BROMS Cohort Study was funded with grant 345-2002-35 from the Swedish Research Council and by the Stockholm County Council. Study sponsors had no role in the design and conduct of the study; collection, management, analysis and interpretation of the data; or preparation, review or approval of the manuscript.

\section{Acknowledgements}

We are grateful to Simon Lind, Peeter Fredlund and Gunilla Björklund for assistance with data analysis.

Mina Rydell, MSc, Department of Public Health Sciences, Karolinska Institutet; Sven Cnattingius, PhD, Fredrik Granath, PhD, Department of Medicine, Karolinska Institutet; Cecilia Magnusson, PhD, Maria Rosaria Galanti, PhD, Department of Public Health Sciences, Karolinska Institutet, Stockholm, Sweden

Correspondence: Mina Rydell, Karolinska Institutet, Department of Public Health Sciences, Division of Public Health Epidemiology, Norrbacka 7th floor, SE-17176 Stockholm, Sweden. Email: mina.rydell@ki.se

First received 25 Jul 2011, final revision 10 Oct 2011, accepted 11 Nov 2011

\section{References}

1 Hellstrom-Lindahl E, Nordberg A. Smoking during pregnancy: a way to transfer the addiction to the next generation? Respiration 2002; 69: 289-93.

2 Slotkin TA, Tate CA, Cousins MM, Seidler FJ. Prenatal nicotine exposure alters the responses to subsequent nicotine administration and withdrawal in adolescence: serotonin receptors and cell signaling. Neuropsychopharmacology 2006; 31: 2462-75.

3 Levin ED, Lawrence S, Petro A, Horton K, Seidler FJ, Slotkin TA. Increased nicotine self-administration following prenatal exposure in female rats. Pharmacol Biochem Behav 2006; 85: 669-74.

4 Hellstrom-Lindahl E, Seiger A, Kjaeldgaard A, Nordberg A. Nicotine-induced alterations in the expression of nicotinic receptors in primary cultures from human prenatal brain. Neuroscience 2001; 105: 527-34.

5 Hernan MA, Hernandez-Diaz S, Werler MM, Mitchell AA. Causal knowledge as a prerequisite for confounding evaluation: an application to birth defects epidemiology. Am J Epidemiol 2002; 155: 176-84.

6 Kendler KS, Thornton LM, Pedersen NL. Tobacco consumption in Swedish twins reared apart and reared together. Arch Gen Psychiatry 2000; 57 886-92.

7 Tyas SL, Pederson LL. Psychosocial factors related to adolescent smoking: a critical review of the literature. Tob Control 1998; 7: 409-20.

8 Oncken C, McKee S, Krishnan-Sarin S, O'Malley S, Mazure C. Gender effects of reported in utero tobacco exposure on smoking initiation, progression and nicotine dependence in adult offspring. Nicotine Tob Res 2004; 6: 829-33.
9 Lieb R, Schreier A, Pfister H, Wittchen H-U. Maternal smoking and smoking in adolescents: a prospective community study of adolescents and their mothers. Eur Addict Res 2003; 9: 120-30.

10 Kardia SL, Pomerleau CS, Rozek LS, Marks JL. Association of parental smoking history with nicotine dependence, smoking rate, and psychological cofactors in adult smokers. Addict Behav 2003; 28: 1447-52.

11 Agrawal A, Knopik VS, Pergadia ML, Waldron M, Bucholz KK, Martin NG, et al. Correlates of cigarette smoking during pregnancy and its genetic and environmental overlap with nicotine dependence. Nicotine Tob Res 2008; 10 : 567-78.

12 Al Mamun A, O'Callaghan FV, Alati R, O'Callaghan M, Najman JM, Williams $\mathrm{GM}$, et al. Does maternal smoking during pregnancy predict the smoking patterns of young adult offspring? A birth cohort study. Tob Control 2006; 15: $452-7$.

13 Cornelius MD, Leech SL, Goldschmidt L, Day NL. Prenatal tobacco exposure: is it a risk factor for early tobacco experimentation? Nicotine Tob Res 2000; 2: $45-52$.

14 Griesler P, Kandel D, Davies M. Maternal smoking in pregnancy, child behavior problems, and adolescent smoking. J Res Adolesc 1998; 8: 159-85.

15 Kandel DB, Wu P, Davies M. Maternal smoking during pregnancy and smoking by adolescent daughters. Am J Public Health 1994; 84: 1407-13.

16 Kandel DB, Griesler PC, Schaffran C. Educational attainment and smoking among women: risk factors and consequences for offspring. Drug Alcohol Depend 2009; 104 (suppl 1): S24-33.

17 O'Callaghan FV, O'Callaghan M, Najman JM, Williams GM, Bor W, Alati R Prediction of adolescent smoking from family and social risk factors at 5 years, and maternal smoking in pregnancy and at 5 and 14 years. Addiction 2006; 101: 282-90.

18 Tehranifar $\mathrm{P}$, Liao $\mathrm{Y}$, Ferris JS, Terry MB. Life course socioeconomic conditions, passive tobacco exposures and cigarette smoking in a multiethnic birth cohort of U.S. women. Cancer Causes Control 2009; 20: 867-76.

19 Roberts KH, Munafo MR, Rodriguez D, Drury M, Murphy MF, Neale RE, et al. Longitudinal analysis of the effect of prenatal nicotine exposure on subsequent smoking behavior of offspring. Nicotine Tob Res 2005; 7: 801-8.

20 Cornelius MD, Leech SL, Goldschmidt L, Day NL. Is prenatal tobacco exposure a risk factor for early adolescent smoking? A follow-up study. Neurotoxicol Teratol 2005; 27: 667-76.

21 Porath AJ, Fried PA. Effects of prenatal cigarette and marijuana exposure on drug use among offspring. Neurotoxicol Teratol 2005; 27: 267-77.

22 Buka SL, Shenassa ED, Niaura R. Elevated risk of tobacco dependence among offspring of mothers who smoked during pregnancy: a 30-year prospective study. Am J Psychiatry 2003; 160: 1978-84.

23 O'Callaghan FV, Al Mamun A, O'Callaghan M, Alati R, Najman JM, Williams $\mathrm{GM}$, et al. Maternal smoking during pregnancy predicts nicotine disorder (dependence or withdrawal) in young adults - a birth cohort study. Aust N Z J Public Health 2009; 33: 371-7.

24 Post A, Galanti MR, Gilliam H. School and family participation in a longitudinal study of tobacco use: some methodological notes. Eur J Public Health 2003; 13: $75-6$.

25 Post A, Gilljam H, Rosendahl I, Bremberg S, Galanti MR. Symptoms of nicotine dependence in a cohort of Swedish youths: a comparison between smokers, smokeless tobacco users and dual tobacco users. Addiction 2010; 105: 740-6.

26 Lindqvist R, Lendahls L, Tollbom ÖR, ÅBerg H, Håkansson A. Smoking during pregnancy: comparison of self reports and cotinine levels in 496 women. Acta Obstet Gynecol Scand 2002; 81: 240-4.

27 Doubeni CA, Reed G, DiFranza JR. Early course of nicotine dependence in adolescent smokers. Pediatrics 2010; 125: 1127-33.

28 Savageau JA, Mowery PD, DiFranza JR. Symptoms of diminished autonomy over cigarettes with non-daily use. Int J Environ Res Public Health 2009; 6 25-35.

29 DiFranza J. A new approach to the diagnosis of tobacco addiction. Addiction 2010; 105: 381-2.

30 DiFranza JR, Savageau JA, Fletcher K, Pbert L, O'Loughlin J, McNeill AD, et al. Susceptibility to nicotine dependence: the Development and Assessment of Nicotine Dependence in Youth 2 study. Pediatrics 2007; 120: e974.

31. Dluzen DE, Anderson LI. Estrogen differentially modulates nicotine-evoked dopamine release from the striatum of male and female rats. Neurosci Lett 1997: 230: 140-2.

32 DiFranza JR, Savageau JA, Rigotti NA, Fletcher K, Ockene JK, McNeill AD, et al. Development of symptoms of tobacco dependence in youths: 30 month follow up data from the DANDY study. Tob Control 2002; 11: 228. 
33 Furberg $\mathrm{H}$, Lichtenstein $\mathrm{P}$, Pedersen NL, Bulik C, Sullivan PF. Cigarettes and oral snuff use in Sweden: prevalence and transitions. Addiction 2006; 101 . 1509.

34 Post A, Gilljam H, Rosendahl I, Meurling L, Bremberg S, Galanti MR. Validity of self reports in a cohort of Swedish adolescent smokers and smokeless tobacco (snus) users. Tob Control 2005; 14: 114-7.

35 Pickett KE, Kasza K, Biesecker G, Wright RJ, Wakschlag LS. Women who remember, women who do not: a methodological study of maternal recall of smoking in pregnancy. Nicotine Tob Res 2009; 11: 1166-74.
36 Shenassa ED, McCaffery JM, Swan GE, Khroyan TV, Shakib S, Lerman C, et al. Intergenerational transmission of tobacco use and dependence: a transdisciplinary perspective. Nicotine Tob Res 2003; 5 (suppl 1): S55-69.

37 Mackay J, Eriksen MP. The Tobacco Atlas. World Health Organization, 2002.

38 Moussa $K$, Östergren $P$, Grahn $M$, Kunst AE, Eek F, Essén B. Socioeconomic differences in smoking trends among pregnant women at first antenatal visit in Sweden 1982-2001: increasing importance of educational level for the total burden of smoking. Tob Control 2009; 18: 92

\section{poem}

\section{Coming to Terms with Schizophrenia}

\section{Barry Tebb}

Why our son, why?

Every morning the same dark chorus wakes me And I wonder how I am still alive.

'Balance the forces of life and death'

Is the Kleinian recipe for survival.

'It is God's will, life is meant to test us'

My Christian heritage tells me.

'Life is a vale of soul making'

Keats reminds us.

Insistently the morning traffic hums

As I sip my tea, list calls to make,

sigh in frustration at unread books.

For solace I look at cards of Haworth

Moorland vistas of unending paths

Cloudscapes only a Constable could paint

High Withens in a gale, the sloping village street.

How? When? Why?

'The truth' - if such an entity exists -

Is that I want to run away

Barry Tebb was born in Leeds in 1942. He is a carer and a prolific poet, Leeds Partnerships NHS Foundation Trust governor and campaigner for better mental health. This poem is from Tranquillity Street: New \& Selected Poems, published by Sixties Press in 2004 and reprinted with permission.

Chosen by Femi Oyebode. 